\title{
Evidence that Charcot-Marie-Tooth Disease with Tremor Coincides with the Roussy-Levy Syndrome
}

\author{
F. Barbieri, A. Filla, M. Ragno' ${ }^{1}$, C. Crisci ${ }^{1}$, L. Santoro' ${ }^{1}$, M. Corona ${ }^{2}$ and G. Campanella
}

\begin{abstract}
We report data on 3 members of a family affected by a dominantly inherited disorder closely resembling Roussy-Levy syndrome (RLS). Electrophysiological findings showed a marked decrease of motor and sensory conduction velocities and EMG signs of mild neurogenic damage. Light and electron microscopy of sural nerve biopsy showed a hypertrophic neuropathy with diffuse onion-bulb formations and marked decrease of large size fibers. Teased fiber preparations evidenced reduced internodal lengths and segmental demyelination. Other data from the literature on RLS are reviewed and discussed. The hypothesis that RLS is not a disease entity but a hypertrophic-type of Charcot-Marie-Tooth disease with essential tremor (HMSN type 1) is strongly supported.
\end{abstract}

RÉSUMÉ: Les auteurs rapportent l'histoire de trois membres d'une même famille atteints d'un désordre héréditaire autosomal dominant qui ressemble de près au Syndrome de Roussy-Levy (RLS). Les données électrophysiologiques montrent une diminution importante des vitesses de conduction motrices et sensitives et des signes à l'EMG d'atteinte neurogène légère. La microscopie lumineuse et photonique d'une biopsie du nerf sural montre une neuropathie hypertrophique avec formations en peau d'oignon et une perte importante des fibres de grand diamètre. Les préparations d'étalonnement montrent une diminution des distances internodales et une démyélination segmentaire. Nous en profitons pour revoir les données de la littérature sur le RLS. Cette revue et les présents résultats favorisent nettement l'hypothèse que le RLS n'est pas une entité distincte, mais une forme hypertrophique de CharcotMarie-Tooth avec tremblement essentiel (HMSN type 1).

Can. J. Neurol. Sci. 1984; 11:534-540

It is generally agreed that several not well-defined syndromes fall within the "border area" between Charcot-Marie-Tooth disease (CMTD) and typical Friedreich's ataxia (FA). These disorders are considered "variants" or "abortive forms" of either CMTD or FA and their diagnosis is difficult. Roussy and Levy (Roussy and Levy, 1926) described one of these syndromes (RLS); however RLS as a disease entity has been challenged by several authors (see Lapresle and Salisachs, 1973; Salisachs, 1976; Salisachs et al., 1982, for references).

We have adopted various approaches to study several cases of FA and FA-like syndromes collected in Campania, a region of Southern Italy (Filla et al., 1981; Campanella et al., 1980; Caruso et al., 1983; Barbieri et al., 1982). Our findings show that this "border area" between CMTD and FA must be reduced or abolished.

Here we report data on 3 members of a family affected by a dominantly inherited hypertrophic neuropathy. On the basis of clinical, neuropathological and electrophysiological data we conclude that RLS cannot be differentiated from the hypertrophic type of CMTD.

\section{CASE Report}

The pedigree of our three cases is illustrated in fig. 1.

Case 1: This man first underwent a neurological consultation at the age of 55 when his eldest child (case 2) came to our observation. At 18 years of age the medical examination for National Service revealed he was affected by thoracic scoliosis and genu valgum, and he had to wear a corset for several years. When examined by us, he complained only of mild general weakness and tremor in the upper limbs, but it is probable that he minimized his disturbances to hide his disability from his family. The neurological examination showed flat feet and genu valgum, thoracolumbar scoliosis with right thoracic curve and left lumbar curve, enhanced thoracic kyphosis which caused a loss of height of $9 \mathrm{~cm}$ from 1943 to 1980. The speech was nasal, snout reflex was positive and palmomental

From the Departments of Neurology and Clinical Neurophysiology(1), Second School of Medicine, and Laboratory of electron Microscopy, Department of Anatomy(2), School of Veterinary Medicine. University of Naples. Naples. Italy.

Reprint requests for the entire supplement (Phase 3, part 3) to: Prof. André Barbeau, Clinical Research Institute of Montreal, 110 Pine Avenue West. Montreal, Quebec. Canada H2W IR7 


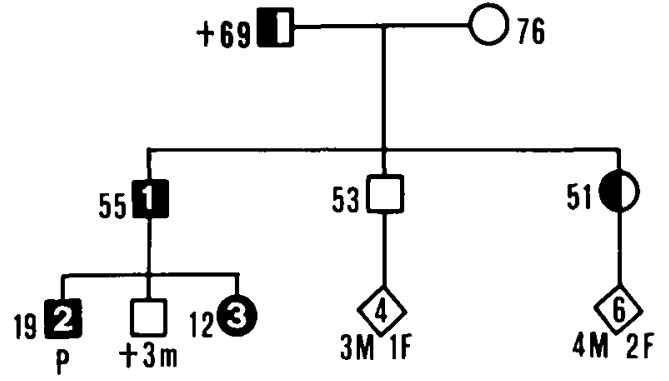

p. index case

affected

$\square$ suspected

Figure 1 - Pedigree of the family.

reflex was present bilaterally. There was muscular wasting and weakness in both hands and in the distal third of both legs. A postural tremor in hands and arms with also intention and action components was evident. Muscle tone was diffusely reduced and arm-pulling test was positive bilaterally. All deep tendon reflexes were absent and plantar responses were indifferent. Vibration sense was reduced in all four limbs ( $9-6 \mathrm{sec}$ with a $128 \mathrm{cps}$ tuning-fork), the other sensations were within normal limits. Romberg's sign was positive. The patient refused electrophysiological examination and sural nerve biopsy.

Case 2: This nineteen years old male, eldest child of case 1 , is our index case. When he was seven years old, he began to complain of weakness in the lower limbs and unsteadiness of gait. More recently he noticed tremor in the upper limbs. These disturbances progressed very slowly. The neurological examination showed bilateral pes cavus, moderate thoracic scoliosis with left curve. Speech was normal. He complained of dysphagia (occasional choking with solids). There was a mild clumsy gait with positive Romberg test, and clumsiness of the hands with moderate incoordination on the finger-to-nose test. Armpulling test was positive bilaterally. Clumsiness of the hands was more evident on manual ability tests (peg-board and automatic counter). A mild intention tremor with postural and action components was present in upper limb extremities.

From time to time a "head-nodder"-like tremor appeared. Fingers were loose-jointed without any evident wasting. Several vegetative signs, such as cold feet and plantar hyperhydrosis were present. There was mild weakness in the four extremities. All deep tendon reflexes were absent and plantar responses were indifferent. Vibration sense was within normal limits in upper limbs and markedly reduced in lower limbs $(3-7 \mathrm{sec})$. Other sensations were normal. The general examination of this patient and of his sister (case 3 ) showed a widespread cutaneous lesion, which was diagnosed as an erythema annulare centrifugum (Dr. M. Delfino, Dept of Dermatology, Second School of Medicine, Naples). These skin disorders, which are probably unrelated to the neurological picture, will be extensively described in a separate paper.

Case 3: This twelve years old girl is the second child of case 1. At age eight, she did not complain of any disorder, but a neurological examination showed absent tendon reflexes, positive arm-pulling test, tremor in writing and bilateral genu valgum. The neurological examination, performed when the patient was 12 years old, showed bilateral pes cavus. Scoliosis was absent and speech was normal. Gait and standing did not show any obvious abnormal features. A slight intention-postural action tremor and an inconstant "head-nodder" tremor were evident. Hands and fingers were loose-jointed without any obvious wasting. Coordination at the 4 limbs was normal, manual ability tests were at the lower limits of normal. Arm-pulling test was positive bilaterally. Mild weakness and hypotonia were present in the four extremities. All deep tendon reflexes were absent; plantar responses were normal. Vibration sense was impaired in the lower extremities $(7-8 \mathrm{sec})$.
The three patients underwent the following laboratory investigations: glucose tolerance test, serum bilirubin, senum cholesterol and triglycerides, ultracentrifugation profile of serum lipoproteins, electrocardiogram and echocardiogram, $X$-rays of chest and spine. Case 2 underwent a pneumoencephalogram with cerebro-spinal fluid examination including IgG; all these tests were within normal limits.

\section{Electrophysiological Findings}

The patients were examined with a DISA 3-channel electromyograph, type 14 A 30 using a conventional technique on biceps brachii and tibialis anterior muscles. Assessment of electromyographic abnormalities was based on type and amplitude of electrical activity during full muscular effort, mean duration of 25-30 different motor unit potentials recorded at weak effort, incidence of polyphasic potentials, and presence at rest of short duration spontaneous activity. Maximum conduction velocity along motor (MCV) and sensory (SCV) fibers of the median nerve was measured at $35-36^{\circ} \mathrm{C}$ near nerve temperature. The sensory conduction was examined orthodromically using the technique described by Buchthal and Rosenfalck (Buchthal and Rosenfalck, 1966).

Our findings on the two siblings (case 2 and 3 ) are summarized in Table 1. We found electromyographic signs of mild to moderate neurogenic damage in the upper and lower limbs. MCV and SCV were the most affected. We found a marked slowing (about $70 \%$ below normal value) of motor and sensory velocity both distally and proximally. The amplitude of sensory potentials was constantly reduced and a marked temporal dispersion was observed. In conclusion, electrophysiological data indicate a polyneuropathy with demyelinating features.

\section{Neuropathological Findings}

A sural nerve biopsy was performed above the lateral malleolus in the two siblings (case 2 and 3). Each specimen was divided into three portions: one for light microscopy, another for electron

Table 1: Electrophysiological data

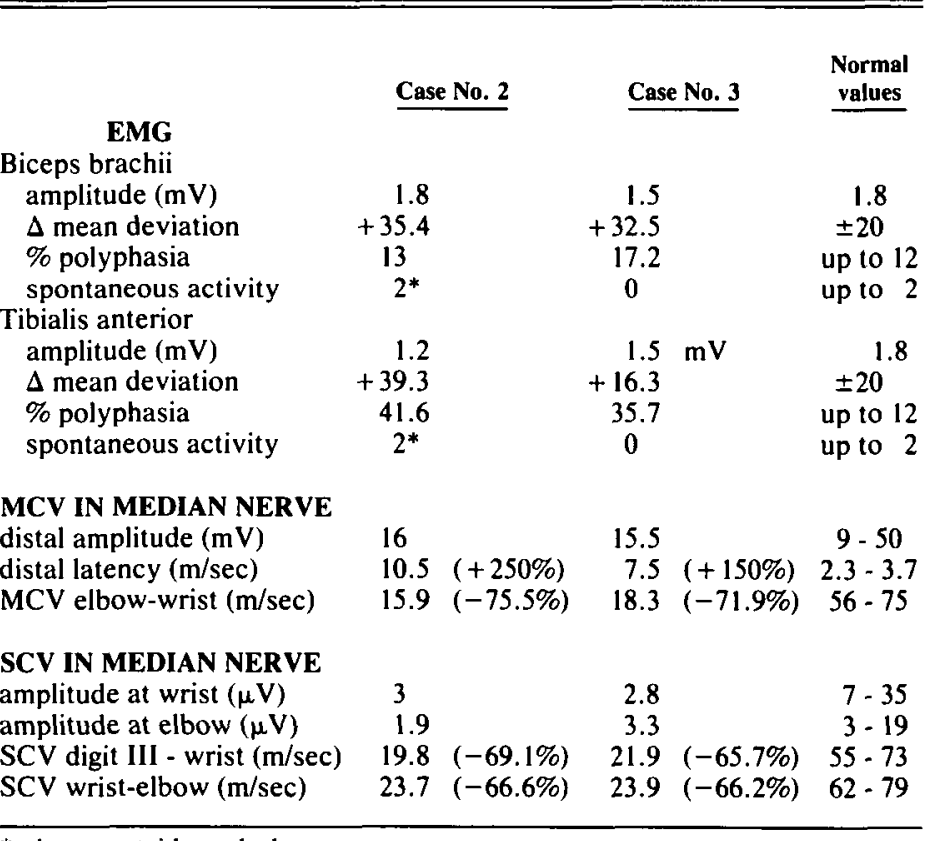

\footnotetext{
* places outside end-plate zone
} 
microscopy and the third for fibre teasing. The fragment for light microscopy was fixed in $2.5 \%$ glutaraldehyde in cacodylate buffer ( $\mathrm{pH} 7.4)$, postfixed in $2 \%$ osmium tetroxide in the same buffer and embedded in Epon 812. Semithin sections of the whole nerve were cut transversally and stained with toluidine blue for light microscopy and morphometry. The second portions was subdivided and processed in the same way. Ultrathin sections were stained with uranyl acetate and lead citrate, and observed with a 201 Philips Electron Microscope. The technique described by Behse et al. (Behse et al., 1972 and 1974; Behse and Buchthal, 1977) was employed for quantitative histology and the teased nerve fiber study.

Case 2 biopsy showed an enlarged sural nerve consisting of nine fascicles. Epineurium and perineurium were normal. Myelinated fibers appeared more scattered than usual and they were surrounded by an increased amount of endoneurial collagen. Endoneurial collagen had a somewhat mucoid appearance and it contained many unmyelinated fibers. The most striking feature was Schwann cell proliferation with onion-bulbs around most of the large fibers. Most of these onion-bulb formations were formed by several whorls of overlapping Schwann cell processes (fig. 2). Some endoneurial capillary walls appeared thickened.

Histometric data for this specimen are shown in Table 2. It is evident that, while the total number of fibres is within normal limits, the density of fibres is greatly reduced as a result of a marked increase of the endoneurial area. Large fibres (diameter

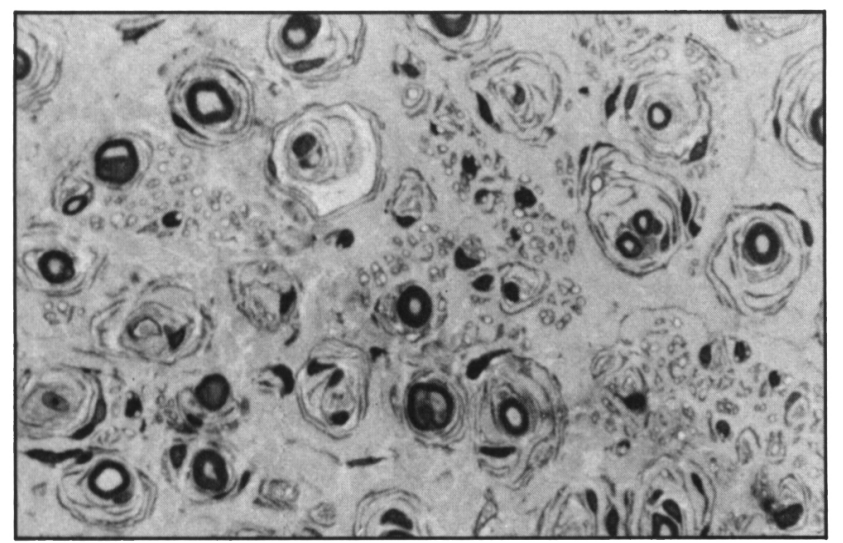

Figure 2 - Case 2. Sural nerve biopsy. Cross section of nerve, showing a comprehensive view of the hypertrophic neuropathy with many multilayered onion bulb formations. (Semithin section: Toluidine blue stain, $x$ 700).

\begin{tabular}{lcccc}
\hline Table 2: Histometric data & & & \\
\hline \hline & Case No. 2 & $\frac{\text { Case No. 3 }}{5,667}$ & & $\begin{array}{c}\text { Normal } \\
\text { values (1) }\end{array}$ \\
Total number of fibers & 2,024 & & 2,711 & $5,200-8,100$ \\
Density of fibers $/ \mathrm{mm}^{2}$ & 2.8 & 2.3 & $6,800-8,500$ \\
Endoneural area $\left(\mathrm{mm}^{2}\right)$ & 19.3 & 24.7 & $0.5-1.3$ \\
$\%$ fibers $\emptyset>7 \mu \mathrm{m}$ & 2.9 & 2.7 & $18.5-29.3$ \\
$\%$ fibers $\emptyset>9 \mu \mathrm{m}$ & 0.4 & 0.12 & $2.8-7.9$ \\
\% fibers $\emptyset>11 \mu \mathrm{m}$ & 24 & 12 & 0 & -20 \\
Number of clusters & & &
\end{tabular}

(1) from Caruso et al. ${ }^{\text {}}$
$>7 \mu \mathrm{m}$ ) are greatly reduced and those larger than $11 \mu \mathrm{m}$ are very rare. The histogram shows a fiber size distribution of the unimodal type (fig. 3).

In thin sections, each onion-bulb was formed by a variable number of successive whorls, in most cases more than 3 (fig. 4).

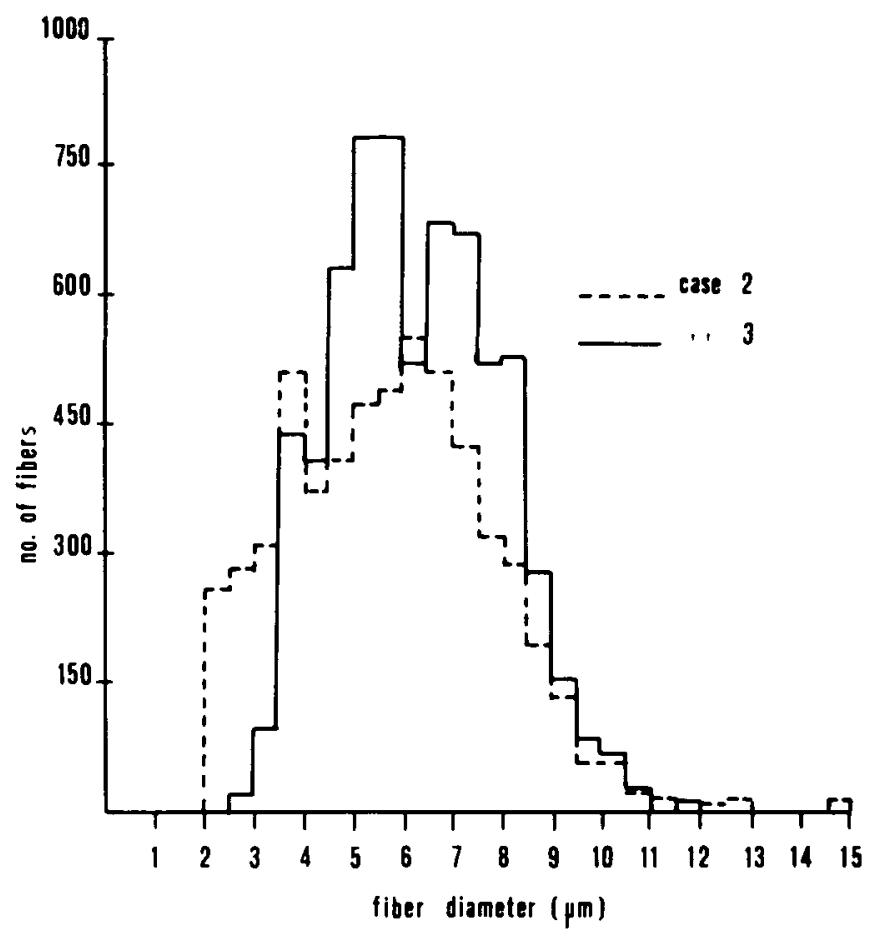

Figure 3 - Histogram of case 2-3 sural nerve biopsies.

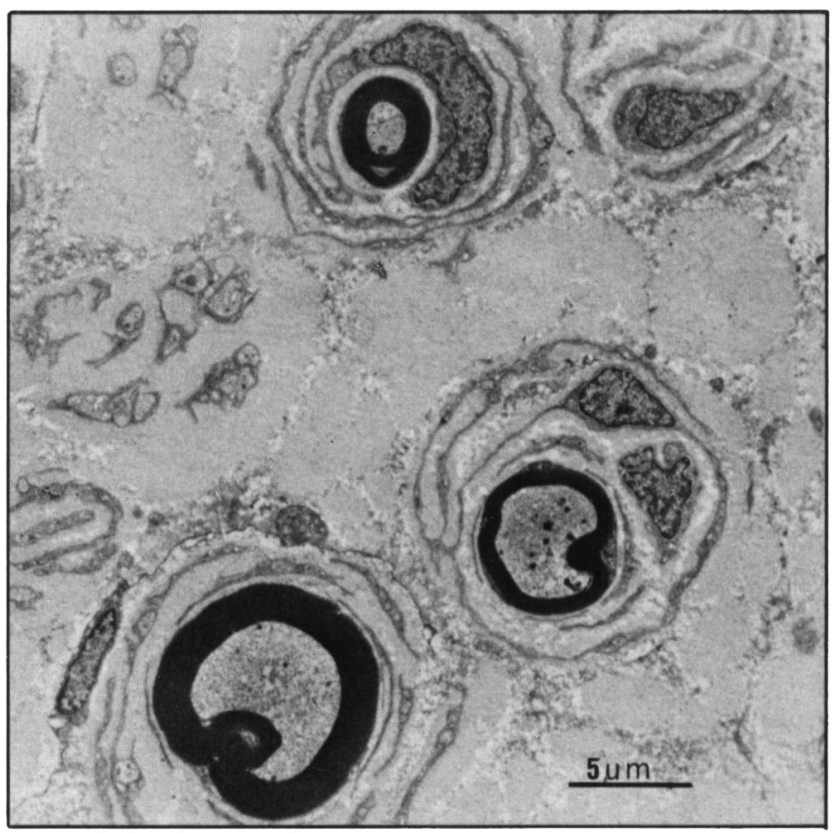

Figure 4-Case 2. Electronmicrograph of sural nerve biopsy, showing a variable number of whorls in each onion bulb (x 3700). 
Each whorl was constituded by flattened overlapping Schwann cell processes, and a dense layer of transversely-sectioned collagen fibrils separated the whorls (fig. 5). The center of some onion-bulb formations contained one or, less frequently, two myelinated fibers; other centers contained unmyelinated axons of different diameters. Nerve structures were sometimes lacking in the core of the whorl. Several whorls contained one or more Schwann cell nuclei, unmyelinated axons and/or collagen pockets (fig. 5). Most of the myelinated fibers had a normal structure, some of them had a very thin myelin sheath in proportion to the size of the axons, thereby suggesting a remyelination process; a few others showed degenerative changes.

In teased nerve preparations, internodal lenghts were greatly reduced and the thickness of the myelin sheath varied considerably from one internode to the next. Segmental demyelination and paranodal enlargments were evident (fig. 6). A quantitative study (i.e. the ratio between internodal length and fiber diameter) was not possible because of the greatly reduced large fibers, the marked proliferation of Schwann processes and the admixture of collagen fibers.

Case 3 biopsy also showed an enlarged sural nerve consisting of eight fascicles. Light microscopy findings were similar to those of the older brother (case 2). However, the picture of generalized onion-bulb formations was less pronounced than in case 2 and the concentric array of Schwann cell processes was constituted by less whorls. Several fibers did not show onionbulb formations.

Histometric data are shown in Table 2. These findings were almost identical to those described for case 2 . The histogram shows a similar unimodal pattern (fig. 3 ).
Thin sections confirm the limited proliferation of Schwann cell processes (fig. 7). In some places instead of typical whorl formations, a proliferation and aggregation of Schwann cells was evident, which probably correspond to the "plaques" described by early pathologists in hypertrophic neuropathies

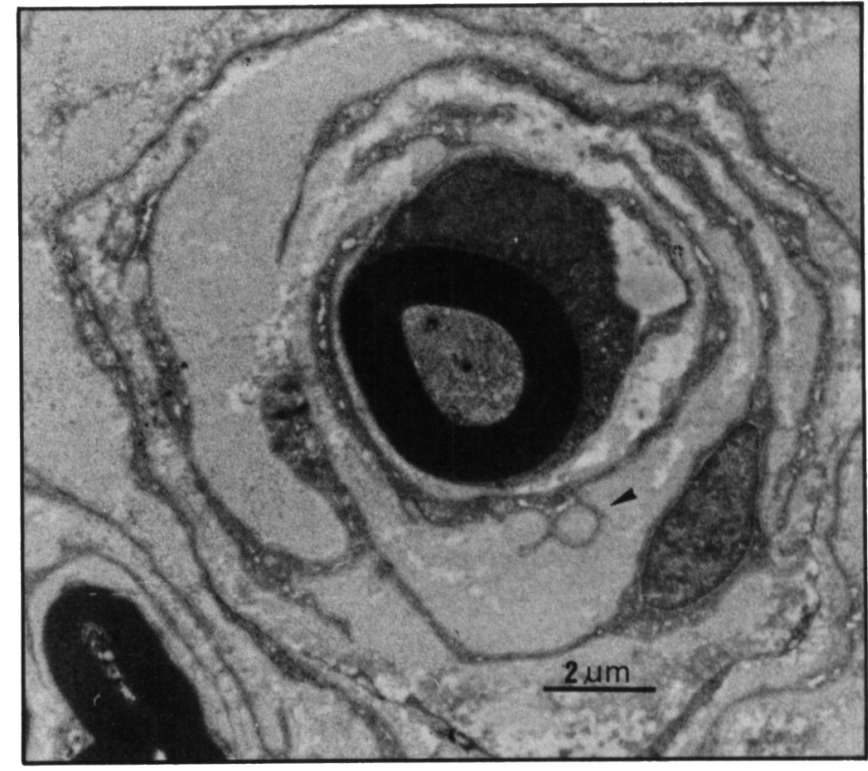

Figure 5 - Case 2. Electronmicrograph of sural nerve biopsy, showing flattened overlapping Schwann processes separated by collagen fibrils and mucoid-like substance; arrow = collagen pocket $(x 8200)$.

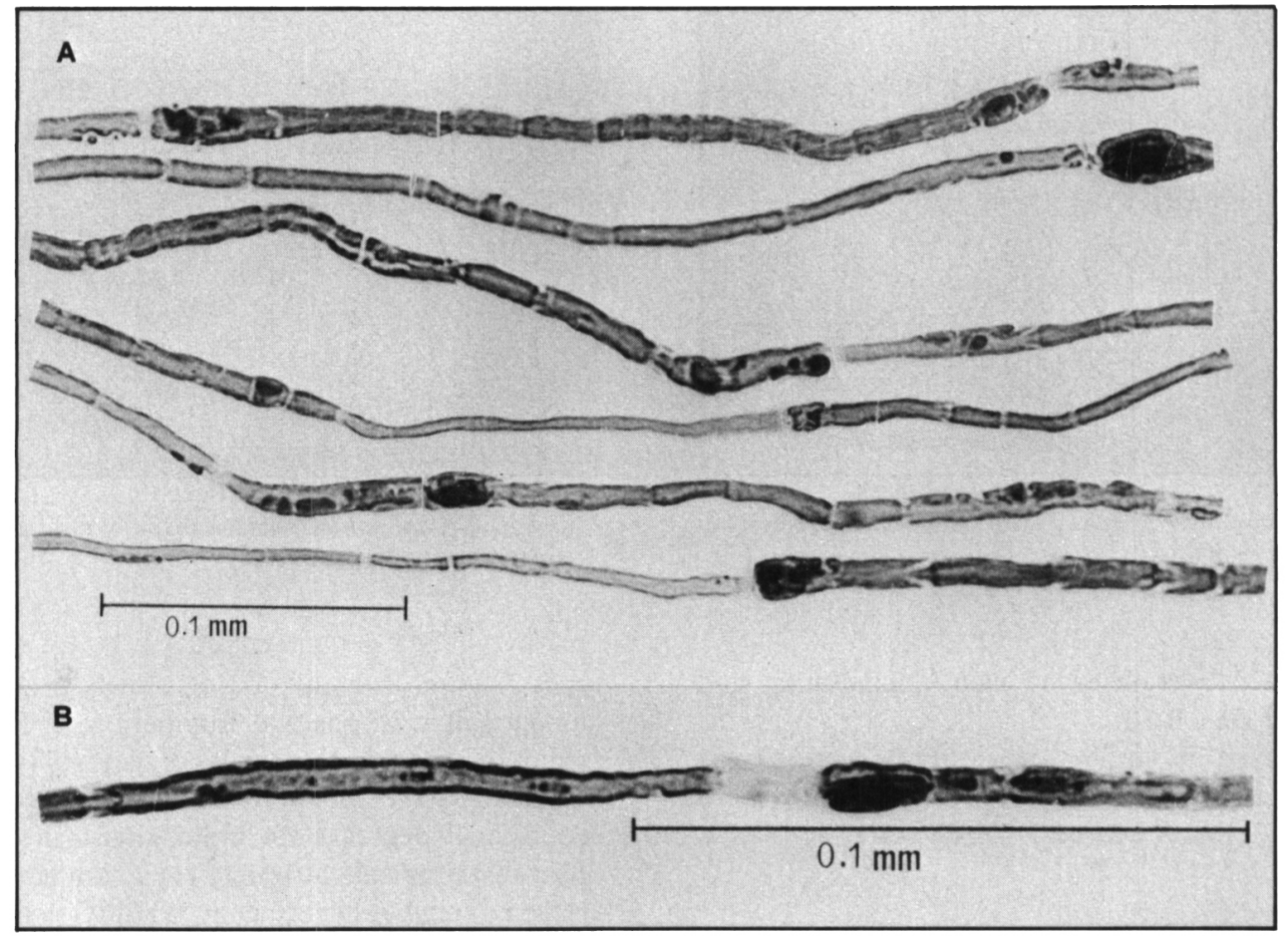

Figure 6 - Case 2. Teased nerve fiber preparation showing greatly variable thickness of the myelin sheath, segmental $(A)$ and paranodal $(B)$ demyelination, and paranodal enlargement $(A=x 410, B=\times 820)$. 


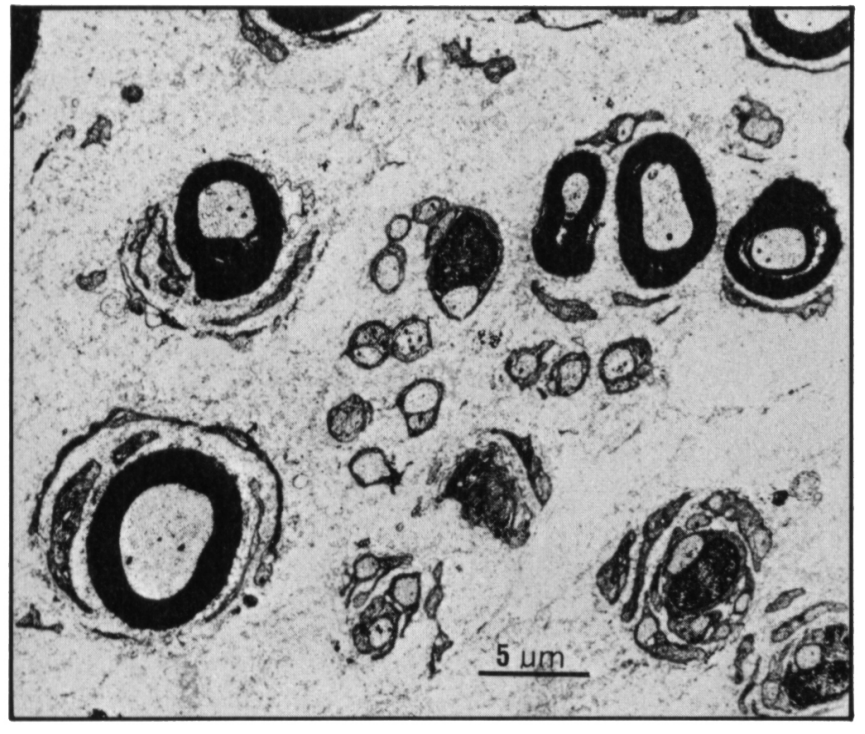

Figure 7-Case 3. Electonmicrograph of sural nerve biopsy, showing a limited proliferation of Schwann cell processes (x 8200).

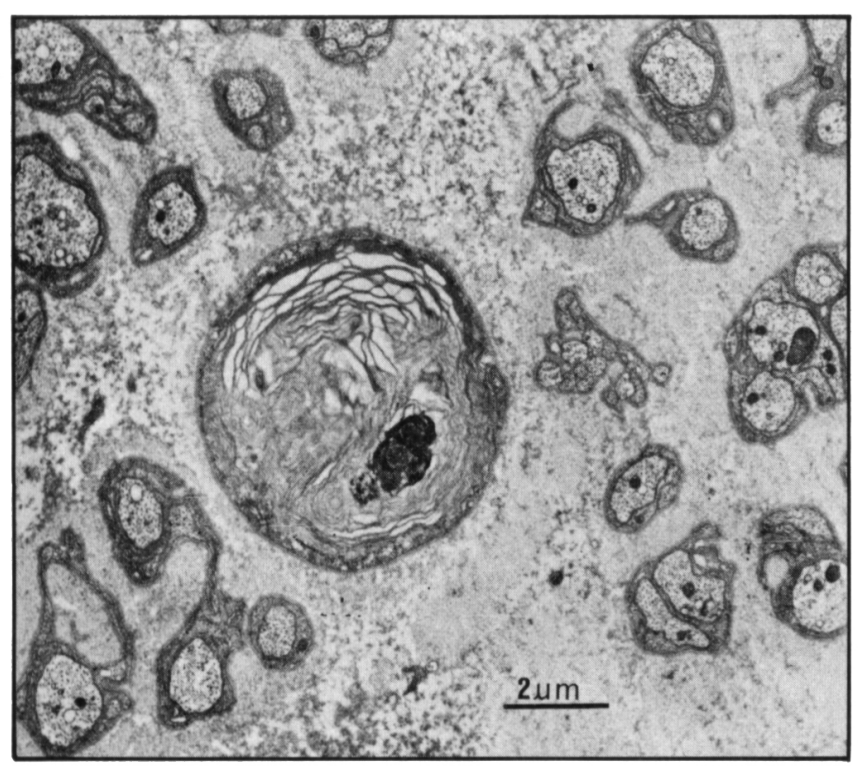

Figure $9-$ Case 3. Electronmicrograph of sural nerve biopsy, showing a degenerating fiber $(x$ 12,300).

(fig. 8). As in case 2, we observed also degenerating and remyelinating fibers (figs. 9-10).

The data from teased nerve fiber preparations were almost identical to those described for case 2; the same features were present, although to a lesser degree.

\section{Discussion}

The same well-defined picture appears in our three patients: 1) an inheritance pattern suggestive of the autosomal dominant

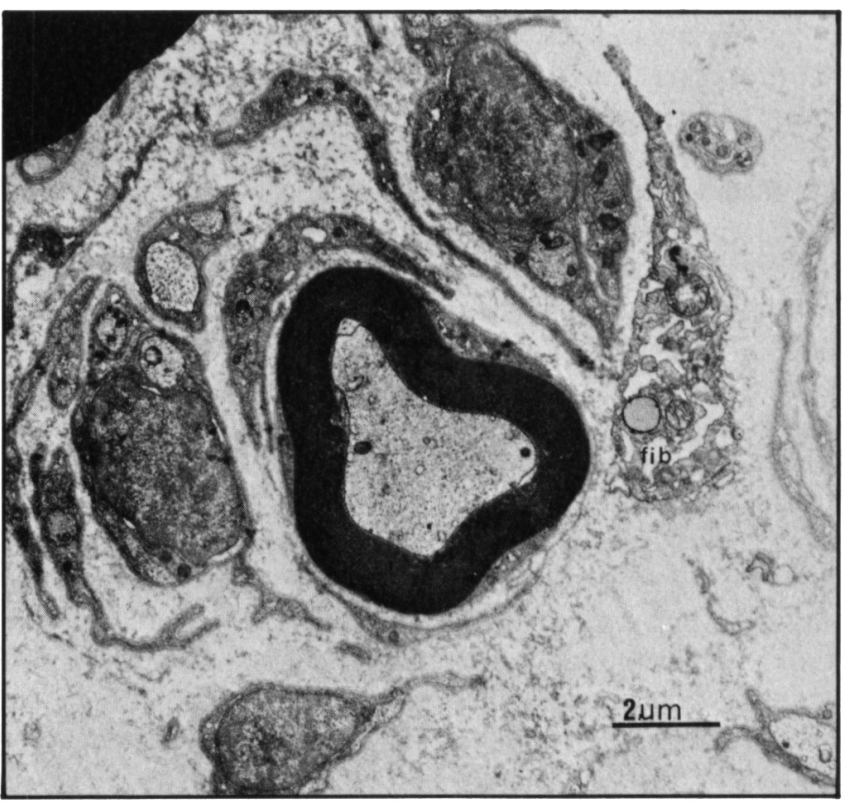

Figure 8-Case 3. Electron-micrograph of plaque-like sural nerve biopsy, showing aproliferation and aggregation of Schwanncells; fib = fibroblast $(x 8200)$.

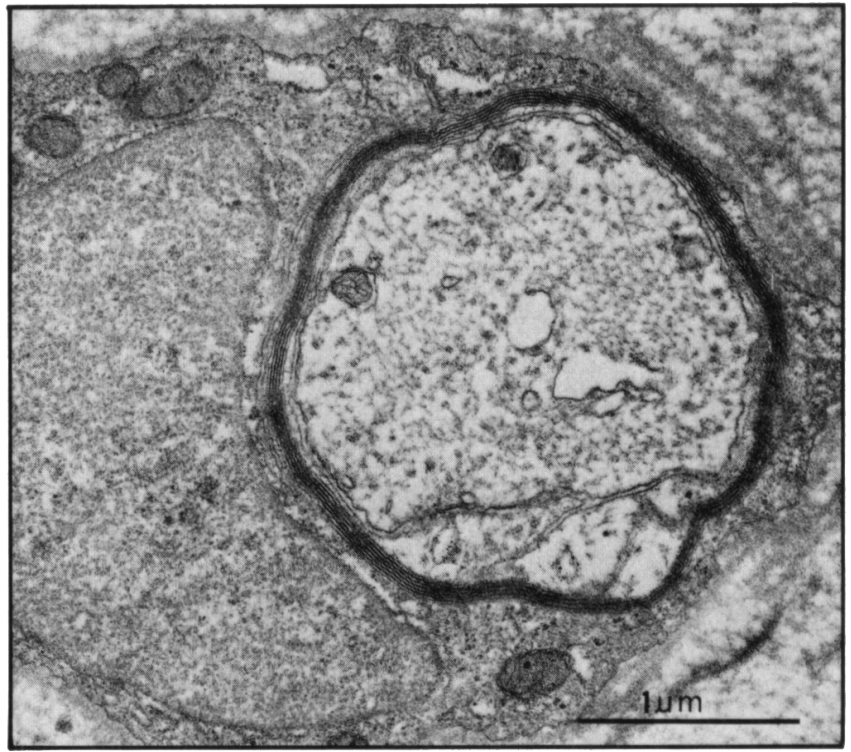

Figure 10 - Case 3. Electronmicrograph of sural nerve biopsy, showing a remyelinating fiber $(x 33,400)$.

type; 2) onset in childhood; 3) slowly progressive course; 4) clumsy gait with positive Romberg test; 5) "essential type" tremor in hands; 6) clumsiness of hands; 7) absent deep tendon reflexes; 8) skeletal deformities (pes cavus, genu valgum, scoliosis); 9) decrease of vibratory sense in lower limbs; 10) late onset distal muscle atrophy; 11) a skin lesion featuring as an erythema annulare centrifugum; 12) EMG signs of mild neurogenic damage; 13) marked decrease of MCV and SCV; 14) hypertrophic neuropathy with diffuse onion-bulb formations and marked decrease of large size fibers in the sural nerve. In our three 
patients the severity of clinical features appears to be related to age and stage of illness.

However, our laboratory findings are not in agreement with this syndrome as a separate clinical entity. Other reports are consistent with our observations.

Yudell et al. (Yudell et al., 1965) found a marked reduction of $\mathrm{MCV}$; in four cases with RLS (19-25 m/sec in the ulnar nerve, $18-28 \mathrm{~m} / \mathrm{sec}$ in the median nerve, no response in the peroneal nerve). Another 5 members of the same kinship with CharcotMarie-Tooth disease (CMTD) showed very similar electrophysiological features. RLS was differentiated from CMTD by the presence of essential tremor in the former. Similar low MCV values had been found by Lascelles et al. (1970). Oelschlager et al. (1965) found lower MCV values in the ulnar nerve (7.0, 7.6 and $9.3 \mathrm{~m} / \mathrm{sec}$ respectively) in three patients with RLS. Paolozzi et al. (1973) found a marked decrease of MCV in 10 out of 12 members of a family with an RLS-like syndrome.

In one of Roussy and Levy's original patients, Lapresle and Salisachs (1973) found a MCV in the ulnar nerve of $15 \mathrm{~m} / \mathrm{sec}$. The same findings were reported by Kriel et al. (1974) in 8 members of another kinship with RLS (MCV in the median nerve: $11-12 \mathrm{~m} / \mathrm{sec}$; in the ulnar nerve: $10-20 \mathrm{~m} / \mathrm{sec}$; in the peroneal nerve: from not recordable to $22 \mathrm{~m} / \mathrm{sec}$ ). None of these authors investigated sensory conduction velocity, which was found to be markedly reduced in the median nerve of our three cases. These data and EMG findings confirm that the electrophysiological picture observed in RLS does not differ from that observed in hypertrophic-type CMTD.

To our knowledge there are only a few neuropathological studies of RLS. Oelschlager et al. (1965) reported very briefly that the histological picture of a sural nerve biopsy in one of their patients revealed "a decrease in the size of the axons and myelin sheaths but no evidence of active degeneration". Lapresle and Salisachs (1973) found a typical picture of hypertrophic neuropathy with numerous onion-bulb formations in one of Roussy and Levy's original patients. Finally, Kriel et al. (1974) in four nerve biopsies found a similar picture of hypertrophic neuropathy, the degree of which varied from patient to patient. Neither quantitative histology nor a teased nerve fibre study has been described previously. Yudell et al. (1965) and Dyck and Lambert (1968) suggested that patients with RLS might be said to have CMTD with a superimposed essential-type tremor. According to Salisachs (1976) the syndromes described by Raymond (1900-1901), Marie (1906), Boveri and Roussy and Levy (1926) are the same clinical entity, which is an association of CMTD and essential tremor (CMTET). Hence, the question arises as to whether RLS is a disease entity or whether it is the hypertrophic type of CMTD (HMSN type 1 ; Dick et al., 1975) which may be sometimes associated with essential tremor(ET).

Although, clinically, our cases fit the description of RLS, our electrophysiological and neuropathological findings are identical to those reported for HMSN type 1 (Dyck et al., 1975). And it should be noted that the other characteristics of RLS such as the early onset, the very slow progression, the early loss of all deep tendon reflexes are also compatible with HMSN type 1.

The observation of features typical of CMTD and of RLS in different members of the same kinship (Yudell et al., 1965; Spillane, 1940) supports the hypothesis that CMTD and RLS are the same disease entity. Salisachs et al. (1982) have recently reported that in a family whose members were believed to have either CMTD or FA, a pathological examination revealed that the case with FA showed only the changes typical of CMTD. We suggest that a similar incorrect distinction has been made between hypertrophic-type CMTD and RLS. Yudell et al. (1965) and Young and Shahani (1979) suggested that ET can be transmitted by a separate dominant gene, but since ET alone is not observed in kinships with CMTD and ET, linkage of genes for CMTD and ET is more probable (Kriel et al., 1974). Cases of neuronal-type CMTD with associated ET have also been reported (Salisachs, 1976; Martinelli et al., 1978).

In conclusion, we think that our cases belong to the large group of hypertrophic-type CMTD and that RLS as originally described cannot be considered a disease entity on electrophysiological and neuropathological grounds. Our data in the three patients described give strong support to the thesis put forward by Salisachs et al. (1982). On the other hand HMSN type 1 which includes hypertrophic-type CMTD is probably an heterogeneous group of syndromes. Only the determination of the biochemical defects will decide which disorders of this group are a separate entity.

\section{REFERENCES}

Barbieri F, Russo E, Corona M and Cecio A (1982) Light and electron microscopic study of the sural nerve biopsies in 13 patients with Friedreich's ataxia. Caryologia 35: 147-148.

Behse, F, Buchthal F, Carlsen F and Knappeis GC (1972) Hereditary neuropathy with liability to pressure palsies. Brain 95: 777-794.

Behse F, Buchthal F, Carlsen F and Knappeis GC (1974) Endoneurial space and its constituents in the sural nerve of patients with polyneuropathy. Brain 97: 773-784.

Behse F and Buchthal F (1977) Peroneal muscular atrophy (PMA) and related disorders. II. Histological findings in the sural nerves. Brain 100: $67-85$,

Boveri P De la névrite hypertrophique familiale (type Pierre Marie). Sem Med Paris 13: 145-150.

Buchthal F and Rosenfalk A (1966) Evoked action potentials and conduction velocity in human sensory nerves. Brain Res 3: 1-122.

Campanella G, Filla A, De Falco FA, Mansi D, Durivage $A$ and Barbeau A (1980) Friedreich's ataxia in the South of Italy: a clinical and biochemical survey of 23 patients. Can J Neurol Sci 7: 351:357.

Caruso G, Santoro L, Perretti A, Serlenga L, Ragno M, Crisci C, Barbieri F and Filla A (1983) Friedreich's ataxia: electrophysiological and histological aspects. Acta Neurol Scand 67: 26-42.

Dyck PJ and Lambert EH (1968) Lower motor and primary sensory neuron diseases with peroneal muscular atrophy. Neurologic, genetic and electrophysiological findings in hereditary polyneuropathies. Arch Neurol 18: 603-618.

Dyck PJ, Thomas PK and Lambert EH (1975) Peripheral neuropathy. Philadelphia: Saunders, pp 834-855.

Filla A, Carlomagno S, Di lorio G, Federico A, Guadagnino $M$ and Campanella G (1981) Epidemiological study of inherited ataxias in Campania (a region of southern Italy). Pharmacology 22: 66-67.

Kriel RL, Cliffer KD, Berry J, Sung JH and Blond CS (1974) Investigation of a family with hypertrophic neuropathy resembling Roussy-Levy syndrome. Neurology (Minneap) 24: 801-809.

Lapresle J and Salisachs P(1973) Onion bulbs in a nerve biopsy specimen from an original case of Roussy-Levy disease. Arch Neurol 29: 346-348.

Lascelles RG, Baker IA and Thomas PK (1970) Hereditary polyneuropathy of Roussy-Levy type with associated cardiomyopathy. Guy Hosp Rep 119: 253-262.

Marie $\mathrm{P}(1906)$ Forme spéciale de névrite interstitielle hypertrophique progressive de l'enfance. Rev Neurol 14: 557-559.

Martinelli P, Pazzaglia P, Montagna P, Tinuper P, Moretto G, Rizzuto $\mathrm{N}$ and Lugaresi $\mathrm{E}$ (1978) Peroneal muscular atrophy (PMA) with postural tremor. In: Canal, N n Pozza G, eds. Peripheral neuropathies. Developments in Neurology 11: 441-446. 
Oelschlager R, White HM and Neil Shimke R (1965) Roussy-Levy syndrome: report of kindred and discussion of the nosology. Arch Neurol 13: 432-440.

Paolozzi C, Bravaccio F, Sanna G, Tata MR and Guazzi GC (1973) Analisi del biotipo neurologico della malattia di Roussy-Levy dedotto dallo studio della famiglia Ver." La malattia dei piedi falsi"'. Acta Neurol 28: 501-531.

Raymond F (1900-1901) Leçons sur les maladies du système nerveux. 3: $346-365 ; 6: 203-227$.

Roussy $G$ and Levy G (1926) Sept cas d'une maladie familiale particulière. Troubles de la marche, piéds bots et aréflexie tendineuse généalisée avec accesoirement légère maladresse des mains. Rev Neurol 2: 427-450.

Salisachs P (1976) Charcot-Marie-Tooth disease associated with "essential tremor". J Neurol Sci 28: 17-40.
Salisachs P, Findley LJ, Codina M, La Torre P and MartinezLage JM (1982) Use and misuse of the Roussy-Levy eponym. J Neurol Neurosurg Psychiatry 45: 938-939.

Salisachs P, Findley LJ, Codina M, La Torre P and MartinezLage JM (1982) A case of Charcot-Marie-Tooth disease mimicking Friedreich's ataxia: is there any association between Friedreich's ataxia and Charcot-Marie-Tooth disease? Can J Neurol Sci 2: 99-104.

Spillane JD (1940) Familial pes cavus and absent tendon jerks: its relationship with Friedreich's disease and peroneal muscular atrophy. Brain 63: 275-290.

Young RR and Shahani BT (1979) In: Klawans HL, ed. Clinical neuropharmacology. New York: Raven Press, pp 139-156.

Yudell A, Dyck PJ and Lambert EH (1965) A kinship with the RoussyLevy syndrome: a clinical and electrophysiologic study. Arch Neurol 13: $432-440$. 